\title{
Treatment of cytomegalovirus retinitis with zidovudine and ganciclovir in patients with AIDS: outcome and toxicity
}

\author{
A B Millar, R F Miller, G Patou, A Mindel, R Marsh, S J G Semple
}

\begin{abstract}
Sixteen patients with the Acquired Immunodeficiency Syndrome (AIDS) and cytomegalovirus retinitis were treated with ganciclovir alone ( 9 patients) or ganciclovir and zidovudine ( 6 patients). The duration of effective treatment, that is the number of weeks during which there was no deterioration in visual symptoms or retinal appearance, was comparable in both groups. However, six of the seven patients receiving concurrent therapy had to cease treatment temporarily because of bone marrow toxicity compared with one of the nine patients treated with ganciclovir alone. It is concluded that continuous concurrent therapy with oral zidovudine and intravenous ganciclovir is not possible unless unlimited supportive therapy including blood transfusion, is available.
\end{abstract}

Cytomegalovirus (CMV) is the commonest cause of retinitis in patients with the acquired immunodeficiency syndrome (AIDS) with a reported incidence of $6-30 \% \%^{1-7}$ Ganciclovir (9 $[1,3-$ dihydroxy-2-propoxymethyl] guanine) is an acyclic nucleoside which is effective in slowing the progression of CMV retinitis in AIDS patients; ${ }^{8-13}$ however, this drug requires life long intravenous administration and its main toxicity is bone marrow depression. The antiviral drug zuidovudine has also been reported to produce regression of CMV retinitis by a hitherto unexplained mechanism. ${ }^{14} 15$ This suggested that treatment of CMV retinitis with both

University College and Middlesex School of Medicine, London

Department of Medicine

A B Millar, R F Miller, S J G Semple

Medical Microbiology

G Patou

Genitourinary Medicine

A Mindel

Western Ophthalmic Hospital, London

R Marsh zidovudine and ganciclovir might be synergistic; however, these drugs had rarely been used concurrently because of their common bone marrow toxicity. We report the results of such treatment in seven patients with AIDS and CMV retinitis and compare them with the results in nine patients treated with ganciclovir alone.

\section{Patients and methods}

Sixteen homosexual males, aged 27-47 years (mean 36.4) with AIDS were studied. Each patient presented with symptoms of visual impairment and was referred for an ophthalmic opinion and retinal photography.

The diagnosis of CMV retinitis was made by one of us (RM) on the basis of typical fundoscopic appearances of (1) periphlebitis (2) perivascular haemorrhages and exudates.

Each patient was treated with ganciclovir at an initial dose of $7.5 \mathrm{mg} / \mathrm{kg} /$ day for 21 days, followed by maintenance therapy of $2.5 \mathrm{mg} / \mathrm{kg} /$ day. Treatment was given daily via an indwelling Hickman catheter and increased by $2.5 \mathrm{mg} / \mathrm{kg} /$ day if visual deterioration occurred. The treatment regime for zidovudine was $200 \mathrm{mg}$ four hourly.

All the patients were monitored for toxicity by having weekly full blood counts and differential white cell counts, and ophthalmic examination. Changes in visual symptoms or retinal appearance were noted weekly. Treatment was considered effective for any week when visual symptoms and retinal appearances remained stable or improved.

Blood transfusions were given if the haemoglobin was below $8 \mathrm{gm} / \mathrm{dl}$. Unacceptable bone marrow toxicity was defined as (1) more than 4 units of blood transfusion required within 14 days to maintain haemoglobin above $8 \mathrm{gm} / \mathrm{dl}(2)$ a total white cell count $<1 \times 10^{9} / 1$. If bone marrow toxicity occurred then treatment with zidovudine (if patient on both drugs) or ganciclovir was stopped until the haemoglobin and/or white cell count had remained above these levels for 14 days (without blood transfusion). 
Table 1 Clinical details and drug efficacy

\begin{tabular}{|c|c|c|c|c|c|}
\hline $\begin{array}{l}\text { Treatment with A) ganciclovir } \\
B \text { ) ganciclovir and zidovudine }\end{array}$ & Patient no & Age (yrs) & Additional pathology & $\begin{array}{l}\text { Drug effective } \\
\text { (weeks) }\end{array}$ & $\begin{array}{l}\uparrow \text { maintenance therapy to } \\
5 \mathrm{mg} / \mathrm{kg} / \text { day (weeks) }\end{array}$ \\
\hline $\mathbf{A}$ & $\begin{array}{l}1 \\
2 \\
3 \\
4 \\
5 \\
6 \\
7 \\
7 \\
8 \\
9\end{array}$ & $\begin{array}{l}27 \\
29 \\
31 \\
31 \\
36 \\
40 \\
41 \\
41 \\
42\end{array}$ & $\begin{array}{l}\text { B cell lymphoma } \\
\text { Kaposi's sarcoma } \\
\text { Kaposi's sarcoma } \\
\text { PCP^, sclerosing cholangitis } \\
\text { Kaposi's sarcoma } \\
\text { Kaposi's sarcoma } \\
\text { HIV encephalopathy } \\
\text { Kaposi's sarcoma } \\
\text { Kaposi's sarcoma }\end{array}$ & $\begin{array}{r}2 \\
20 \\
8 \\
22 \\
16 \\
17 \\
41 \\
2 \\
20\end{array}$ & $\begin{array}{l}\bar{z} \\
\overline{4} \\
\frac{4}{z} \\
-\end{array}$ \\
\hline B & $\begin{array}{l}1 \\
2 \\
3 \\
4 \\
5 \\
6 \\
7\end{array}$ & $\begin{array}{l}32 \\
33 \\
34 \\
37 \\
39 \\
40 \\
47\end{array}$ & $\begin{array}{l}\text { PCP` } \\
\text { HIV encephalopathy } \\
\text { Kaposi's sarcoma } \\
= \\
\overline{-} \\
\text { Kaposi's sarcoma }\end{array}$ & $\begin{array}{r}12 \\
20 \\
17 \\
41 \\
3 \\
36 \\
17\end{array}$ & $\frac{\bar{z}}{\frac{5}{4}}$ \\
\hline
\end{tabular}

$\star \mathrm{PCP}$-pneumocystis carinii pneumonia.

\section{Results}

All the patients reported some improvement in their symptoms when treatment was commenced and this was confirmed on retinal examination. Nine patients were treated with ganciclovir alone and seven patients were treated with concurrent ganciclovir and zidovudine, the clinical details and outcome are shown in table 1 . There was no significant difference between the two groups in terms of age, duration HIV antibody positive prior to developing CMV retinitis, or initial haemoglobin and white cell counts. Both regimes were equally effective in terms of the weeks for which visual symptoms and retinal appearances were stable. The haematological parameters of both groups are shown in table 2 . There were greater transfusion requirements in patients on concurrent treatment with ganciclovir and zidovudine than in those on ganciclovir alone ( $p<0.05$, Fisher's exact test) such that treatment with zidovudine was temporarily stopped in six of the seven patients on both drugs. The relative risk of treatment withdrawal on concurrent therapy, because of toxicity was $7 \cdot 5(95 \%$ confidence interval $1 \cdot 14$ to $49 \cdot 26) .^{16}$

\section{Discussion}

Cytomegalovirus retinitis has a poor prognosis in patients with AIDS and prior to the development of ganciclovir there was no available therapy. This drug inhibits CMV replication in vitro, and in vivo has been reported as successful in the treatment of various forms of $\mathrm{CMV}$ infection including retinitis. ${ }^{813}$ The major drawbacks of this treatment are the need for long term intravenous maintenance therapy and the toxic effect on the bone marrow.

At the time of this study, the antiviral agent zidovudine had been shown to prolong survival and decrease the frequency of opportunistic infections in

Table 2 Haematological effects of treatment with ganciclovir and zidovudine and resultant supportive therapy required

\begin{tabular}{|c|c|c|c|c|c|}
\hline & Patient no & $\begin{array}{l}\text { Initial/nadir } \\
\mathrm{Hb} \mathrm{g} / \mathrm{dl}\end{array}$ & $\begin{array}{l}\text { Initial/nadir WCC } \\
(\text { neutrophils }) \times 10^{9} / l\end{array}$ & $\begin{array}{l}\text { Initial/nadir } \\
\text { platelets } \times 10^{9} / l\end{array}$ & $\begin{array}{l}\text { Change in treatment and/or supportive } \\
\text { therapy required }\end{array}$ \\
\hline$A^{\star}$ & $\begin{array}{l}1 \\
2 \\
3 \\
4 \\
5 \\
6 \\
7 \\
8 \\
9\end{array}$ & $\begin{array}{c}10 \cdot 0 / 7 \cdot 2 \\
9 \cdot 2 / 6 \cdot 6 \\
10 \cdot 0 / 7 \cdot 0 \\
10 \cdot 3 / 8 \cdot 0 \\
12 \cdot 4 / 8 \cdot 4 \\
8 \cdot 9 / 8 \cdot 4 \\
12 \cdot 9 / 10 \cdot 0 \\
12 \cdot 9 / 8 \cdot 0 \\
8 \cdot 7 / 7 \cdot 8\end{array}$ & $\begin{array}{l}2.7(1.6) / 1.9(1.5) \\
1.7(1.2) / 0.8(0.35) \\
2.8(1.3) / 1.2(0.9) \\
3.5(2.5) / 2.6(2.1) \\
4.9(3.8) / 2.1(1.4) \\
3.3(2.4) / 1.5(0.8) \\
6.8(3.8) / 3.6(2.0) \\
1.8(1.5) / 1.4(0.8) \\
2.7(1.6) / 1.9(1.5)\end{array}$ & $\begin{array}{l}176 / 159 \\
188 / 89 \\
150 / 110 \\
114 / 97 \\
200 / 163 \\
141 / 137 \\
138 / 111 \\
153 / 114 \\
97 / 84\end{array}$ & $\begin{array}{l}\text { Blood transfusion } \times 4 \text { units } \\
\text { Bone marrow failure ? cause ganciclovir stopped } \\
\bar{B} \\
\text { Blood transfusion } \times 3 \text { units } \\
\overline{-} \\
\bar{B} \\
\text { Blood transfusion } \times 4 \text { units } \\
\text { Blood transfusion } \times 4 \text { units }\end{array}$ \\
\hline \multirow[t]{5}{*}{$\mathbf{B}^{\star}$} & 1 & $11 \cdot 2 / 8 \cdot 0$ & $1.89(1.4) / 1.7(1.0)$ & $127 / 73$ & \multirow{5}{*}{$\begin{array}{l}\text { zidovudine stopped because of anaemia. } \\
\text { Blood transfusion } \times 16 \text { units } \\
\text { zidovudine stopped because of anaemia. } \\
\text { Blood transfusion } \times 8 \text { units } \\
\text { zidovudine and ganciclovir stopped because of } \\
\text { anaemia and } \uparrow W C C \text {. } \\
\text { Blood transfusion } \times 8 \text { units } \\
\text { zidovudine stopped because of anaemia. } \\
\text { Blood transfusion } \times 8 \text { units } \\
\text { zidovudine stopped because of low WCC } \\
\text { Blood transfusion } \times 8 \text { units zidovudine stopped } \\
\text { because of low WCC }\end{array}$} \\
\hline & $\begin{array}{l}2 \\
3\end{array}$ & $\begin{array}{l}11 \cdot 8 / 10 \cdot 1 \\
11 \cdot 6 / 7 \cdot 5\end{array}$ & $\begin{array}{l}2 \cdot 4(1 \cdot 2) / 1 \cdot 1(0 \cdot 5) \\
4 \cdot 1(3 \cdot 8) / 2 \cdot 4(1 \cdot 3)\end{array}$ & $\begin{array}{l}107 / 91 \\
112 / 82\end{array}$ & \\
\hline & 4 & $8 \cdot 6 / 6 \cdot 2$ & $1.4(1.0) / 0.8(0.6)$ & $112 / 43$ & \\
\hline & 5 & $12 \cdot 4 / 8 \cdot 0$ & $4.9(3.2) / 2.0(0.9)$ & $132 / 62$ & \\
\hline & $\begin{array}{l}6 \\
7\end{array}$ & $\begin{array}{l}11 \cdot 7 / 8 \cdot 1 \\
10 \cdot 1 / 8 \cdot 5\end{array}$ & $\begin{array}{l}2.0(1.9) / 1 \cdot 2(1.0) \\
3.9(2 \cdot 3) / 1 \cdot 0(0 \cdot 6)\end{array}$ & $\begin{array}{l}115 / 75 \\
109 / 77\end{array}$ & \\
\hline
\end{tabular}

\footnotetext{
${ }^{\star}$ Treatment with (A) ganciclovir (B) glanciclovir and zidovudine.
} 
patients with AIDS and ARC. ${ }^{17}$ These effects may be due to an immunomodulating effect of zidovudine, although documented changes in $\mathrm{CD}_{4}$, numbers have been transient. ${ }^{17}$ There have been reports of regression of CMV retinitis in AIDS patients treated with this drug which has no direct anti CMV effect. ${ }^{14} 15$ This may be comparable with the regression in CMV retinitis which occurs on reversal of transient immunodeficiency states. ${ }^{18}$ Another explanation, as suggested by Skolnick, might be that infection with HIV and CMV increases replication of both viruses and hence inhibition of either would slow down progression of both. ${ }^{19}$ It would seem likely in view of these findings that concurrent therapy with ganciclovir and zidovudine would be advantageous in AIDS patients with CMV retinitis, but they have rarely been given in this way because of their shared toxicity to the bone marrow. One report of such treatment found it possible to use the drugs concurrently but gave unlimited transfusion (average $2 \cdot 4$ units per patient) and reduced treatment on the basis of granulocytopenia alone.$^{20}$ In this study the patients were given ganciclovir $5 \mathrm{mg} / \mathrm{kg} /$ day for five or seven days per week as maintenance therapy. At the time of our study the recommended dose of maintenance therapy for ganciclovir was $2.5 \mathrm{mg} / \mathrm{kg} /$ day and despite this we had considerable tranfusion requirements, such that zidovudine treatment was withdrawn temporarily in six of the seven patients. We found no evidence of synergism in terms of duration of retinal stabilisation, but as zidovudine was stopped in so many cases synergy was not adequately assessed.

Many of our patients had abnormal haematological parameters prior to ganciclovir treatment which may have contributed to the cytopenias which developed in many, and other forms of therapy should be considered in this situation. Foscarnet is an alternative anti-CMV agent which has little haematological toxicity and may be combined with zidovudine therapy; however it may produce electrolyte disturbances and nephrotoxicity and is administered over a prolonged period. ${ }^{21}$

We consider that the toxic effects of concurrent therapy with ganciclovir and zidovudine are unacceptable and we suggest that the use of alternative methods of drug delivery should be further explored. Intravitreal injections of ganciclovir and the newer anti CMV agent foscarnet have been reported to meet with some success. ${ }^{22-24}$ Concurrent therapy with zidovudine and intravitreal anti CMV therapy might produce synergistic effects without the considerable toxicity we have encountered.

We thank Annette Skinner, Kate Young and Jane Catchpole for their expert secretarial assistance.

Correspondence to: Dr A Millar, Academic Dept of Medicine, Middlesex Hospital, Mortimer St, London W1N 8AA, UK
1 Laskin OL, Stahl-Bayliss CM, Kalman CM, Rosecan LR. Use of Ganciclovir to treat serious cytomegalovirus infections in patients with AIDS.J Inf Dis 1987;155:323-7.

2 Jacobson MA, Mills J. Serious cytomegalovirus disease in the acquired immunodeficiency syndrome (AIDS). Ann Int Med 1988;108:585-94.

3 Palestine AG, Rodrigues MM, Macker AM, et al. Ophthalmologic involvement in acquired immune deficiency syndrome. Ophthalmology 1984;91:1092-9.

4 Khadem M, Kalish S, Goldsmith JA, et al. Ophthalmologic findings in acquired immune deficiency syndrome (AIDS). Arch Ophthalmol 1984;102:201-6.

5 Holland GN, Pepose JS, Pettit TH, et al. Acquired immune deficiency syndrome. Ocular manifestations. Ophthalmology 1983;90:859-73.

6 Friedman AH, Orellana J, Feeman WR, et al. Cytomegalovirus retinitus: a manifestation of the acquired immunodeficiency syndrome (AIDS). Br J Ophthalmol 1983;67:372-80.

7 Collaborative DHPG treatment study group. Treatment of serious cytomegalovirus infections with 9-1,3 (dihydroxy-2propoxymethyl) guanine in patients with AIDS and other immunodeficiencies. N Engl J Med 1986;314:801-5.

8 Felsenstein DM, D'Amico DJ, Hirsch MS, et al. Treatment of cytomegalovirus retinitis with $9-[2$ hydroxy-1 hydroxymethyl)] ethoxymethyl guanine. Ann Intern Med 1985;103:377-80.

9 Masur $H$, Clifford Lane $H$, Palestine A. Effect of 9-1,3 dihydroxy-2-propoxymethyl) guanine on serious cytomegalovirus disease in eight immunosuppressed homosexual men. Ann Intern Med 1986;104:41-4.

10 Harris ML, Matholone MBR. Dihydroxypropoxymethyl guanine in the treatment of AIDS related retinitis due to cytomegalovirus. $\mathrm{Br}$ Med J 1987;155:294:92

11 Holland GN, Sakamoto MJ, Hardy D, Sidikaro Y, et al. Treatment of cytomegalovirus retinopathy in patients with acquired immunodeficiency syndrome. Arch Ophthalmol 1986;104:1794-1800.

12 Jabs DA, Newman C, De Bustros S, Polk BF. Treatment of cytomegalovirus retinitis with Ganciclovir. Ophthalmology 1987;94:824-30.

13 Orellana J, Teich SA, Winterburn JS, Mathur-Wagh U, et al. Treatment of cytomegalovirus retinitis with ganciclovir 9[2(hydroxy-1-hydroxymethyl) ethoxymethyl] guanine BW B759U). Br J Ophthalmol 1988;72:525-9.

14 Guyer DR, Jabs DA, Brant AM, Bescharner WE, Green WR. Regression of cytomegalovirus retinitis with zidovudine. A clinicopathologic correlation. Arch Ophthalmol 1989;107: 868-74.

15 D'Amico DJ, Skolnick PR, Kosloff, et al. Resolution of cytomegalovirus with zidovudine therapy.Arch Ophthalmol 1988;106:1168-9.

16 Morris JA, Gardner MJ. Calculating confidence intervals for relative risks (odds ratios) and standardised ratios and rates. $\mathrm{Br}$ Med J 1988;196:1313-16.

17 Fischl MA, Richmann DD, Grieco MH, et al. The efficacy of 3azido-3-deoxythymidine (azidothymidine) in the treatment of patients with AIDS and AIDS-related complex: a doubleblind placebo-controlled trial. $N$ Engl J Med 1987;317: 185-91.

18 Egbert PR, Pollard RB, Gallagher JG, Merigan TC. Cytomegalovirus retinitis in immunocompromised hosts, II: ocular manifestations. Ann Intern Med 1980;93:664-70.

19 Skolnick PR, Kosloff BR, Hirsch MS. Bidirectional interactions between human immunodeficiency virus type 1 (HIV 1) and cytomegalovirus. J Infect Dis 1988;157:508-14.

20 Nussbaum J, Antoniskis D, Causey D, Leedom JM. Toxicity of combined AZT/ganciclovir (DHPG) therapy in AIDS patients [Abstract] Abstracts from the Vth International Conference on AIDS. Montreal: Canadian International Development Research Centre 1989:195.

21 Aweeka F, Gambertoglio J, Mills J, Jacobson MA. Pharmacokinetics of intermittently administered intravenous foscarnet in the treatment of acquired immunodeficiency syndrome patients with serious cytomegalovirus retinitis. Antimicrob Agents Chemother 1989;33:724-45.

22 Walsley S, Chew E, Fanning MM, et al. Treatment of cytomegalovirus retinitis with trisodium phosphonoformate [Abstract] Abstracts from the III International Conference on AIDS. Washington DC: US Dept of Health and Social Services 1987:158.

23 Harris ML, Mathews MBR. Intravitreal ganciclovir in CMV retinitis: a case report. $B r J$ Ophthalmol 1989;75:382-4.

24 Jabs DA, Enger C, Bartlett JD. Cytomegalovirus retinitis and acquired immunodeficiency syndrome. Arch Ophthalmol 1989;107:75-80.

Accepted 23 January 1990 